\title{
Technological Decentralization and Livestock Data Management in Kenya: The Moderating Effect of Blockchain Technology
}

\author{
Leonard Muganda ${ }^{1}$, Jasper Ondulo ${ }^{2}$, Dorothy Rambim ${ }^{3}$
}

Computing \& Informatics, Masinde Muliro University of Science and Technology, Kakamega, Kenya ${ }^{1}$

Lecturer, Computing \& Informatics, Masinde Muliro University of Science and Technology, Kakamega, Kenya ${ }^{2,3}$

\begin{abstract}
The objective of this study is twofold; one, is to assess the impact of Technological Decentralization on Livestock Data Management and two, is to test the moderating effect of Blockchain Technology between Technological Decentralization and Livestock Data Management in Kenya. Technological Decentralization relate to the shift from concentrated distributed modes of technology governance while Blockchain Technology is a distributed encrypted database that serves as incorruptible repository of information. The study adopted a cross-sectional survey design and questionnaires on a 5-poing likert scale to collect data from 361 respondents from institutions dealing with livestockrelated-data. All metrics for Technological Decentralization, Blockchain Technology and Livestock Data Management were analyzed. Hierarchical regression results show that Blockchain Technology positively and significantly moderates between Technological Decentralization and Livestock Data Management. Considering the value of livestock data, enhancing Technological Decentralization and adopting the use of Blockchain Technology, institutions and governments can have leverage on Livestock Data Management.
\end{abstract}

Keywords: Blockchain Technology, Livestock Data Management, Technological Decentralization, Trust, Traceability

\section{INTRODUCTION}

Globally, livestock data is essential for diverse applications in decision making, regular monitoring, planning, policy and investment purposes [1]. This is true for most African countries especially Kenya where livestock data plays a key role in evidence-based decisions and policy formulation, food and nutrition security, planning and development [2]. The need for information from core livestock data in various livestock domains has led to establishment of world livestock databases such as Gridded Livestock of the World database (GLW3) to collect, harmonize, predict and disseminate subnational global livestock data [3]. Implementation of such databases requires that countries identify core livestock data needed for formulation, implementation and effective monitoring sector investments [4]. Developing countries like Kenya have established key institutions dealing with livestock-related-data since pre independence era. These institutions have managed data differently depending on their institutional mandate [5]. Key sources and consumers of these data are farmers who require feedback for decision making; livestock recording institutions for processing and generation of information on breeds, production and markets trends; research organizations for undertaking research; livestock genetic institution; financial institutions \&; government for national planning purposes through National Statistical Authority [5] According to Pica-Ciamarra et al. [1], most developing countries have challenges in managing livestock data (mainly data collection and reporting). In the case of Kenya, there exists a number of challenges in livestock data collection, collation and analysis, thus leading to continual use of institutional data most of which are mere estimates [6]. Gabriel and Willy [6] acknowledge that this trend has compromised the reliability, quality and accuracy of the livestock data. Additionally, the data is scattered across different departments and agencies within the sub sector and lacks a central point of reference resulting to lack of uniform reporting and hence unreliability of livestock data [6].

The increased adoption of Information Communication Technology (ICT) use by institutions has revolutionized how livestock data is managed [7]. Kenya has witnessed an increasing growth of smart phones and smart devices in the past decade [8]. One emerging aspect is the adoption Internet of Things (IoTs) in administering control over livestock data to promote efficiency and service delivery [9]. However, various attempts of incorporating ICTs in the agricultural-livestock sector has revealed that there lacks agreeable livestock data sharing and access of information such as productivity, marketing and commodity use [10]. The use of Blockchain Technology (BCT), a growing technology based on distributed ledger technologies has gained popularity and is being adopted for solving problems associated with scalability and throughput, data security, performance and robustness in decentralized environments [11].

This study creates an understanding on the association between Technological Decentralization (TD) issues and Livestock Data Management (LDM) by assessing the moderating effect of BCT on this relationship. The study reveals that BCT positively and significantly moderates the relationship between TD and LDM. This greatly informs the policy 


\title{
International Journal of Advanced Research in Computer and Communication Engineering
}

\author{
Vol. 9, Issue 5, May 2020
}

makers, researchers, software developers and livestock data experts in understanding the important constructs for design, adoption and implementation of BCT in management of livestock data.

\section{LITERATURE REVIEW}

\section{A. Livestock Data Management}

According to Fasil et al. [12], livestock data comprise of a wide variety and volume (Small and Big Data) essential for decision making and facilitating socio economic growth. They are of the opinion that livestock data has the potential benefits of transforming the livestock sector of developing countries. Additionally, they state that lack of timely and accurate livestock data, makes it increasingly difficult to meet growing demand for animal products and equally to stay competitive in the international market. Data in Kenyan livestock sub sector plays a key role in planning, evidence-based decisions and policy formulation, food and nutrition, security and development of breeding programmes [13]. Managing this data is therefore critical in most growing economies. The increasing use of ICTs to generate and manage livestock data has been triggered by steady growth of mobile telephony especially smart phones and internet coverage [8]. Previous research by Gakuru, et al.[14] and Rosebella, et al.[10], have documented emerging ICT innovations tools (such as farmer advisory services, mobile apps and web portals) used by various agriculture and livestock sector institutions in Kenya. However, these studies mainly focus on their increased adoption and how data has increasingly been collected. Studies by Pica-Ciamarra et al. [1] and Gabriel and Willy [6] confirm that there exists challenges with collection, accuracy, trust, traceability, accessibility and sharing of livestock data. Consequently, there are large knowledge gaps due to institutions collecting own data with little or no coordination with the rest [1].

\section{B. Technological Decentralization}

According to Prachi [15], decentralization is a systematic delegation of authority at all levels of management and in all of the organization. Within the agricultural-livestock sectors, decentralization has been defined as a means to improving sector performance through, service delivery, improving the efficiency, responsiveness and local accountability of extension services and systems [16]. Decentralization aims at bringing services closer to people and allow for closer participation and access to services by the local community hence improving efficiency and innovation.

The concept of TD is defined as the shift from concentrated distributed modes of production and consumption of goods and services not only in digital domain but in other areas where human interaction is involved [17]. In the context of digital domain, this study adopts the definition by Vitalik [18], which focus on software decentralization, a context of software technology use in a distributed environment. We further expound on this definition by explaining software decentralization in terms of infrastructural and architectural issues as a measure of the level of infrastructure capability of information systems; political issues as a measure of the level of control by computer systems and resources; logical issues, a measure of the level of independence of systems interfaces and structures; Data access, retrieval and sharing issues, a measure of the need for institutional data access and retrieval; database systems and data sources, a measure of the need for agreed and distributed data sources among these institutions [18].

In Kenya, decentralization has been widely adopted in many institutions as a means of upscaling development from the lowest level. A number of development sectors have implemented decentralization in their functions and service delivery. Such sectors include health, county government administration, etc [19]. Looking at the agriculture-livestock sector, there has been increased use of ICT in collection, processing, storage and dissemination of livestock data and new innovations has been made by a number of institutions dealing with livestock-related data [10]. The increased use of ICTs by the government and in institutions dealing with livestock-related-data, address the afore mentioned TD issues differently [6]. A good example is when details of the same animal are captured differently by three institutions; say the veterinary department office, livestock recording office and livestock insurance company. The details are then stored in their respective databases bearing different identification information and details of the same animal. Without an agreed framework on validity and data provenance, the data becomes inconsistent, inaccurate and remains duplicated across databases which affects decision-making. This poses the need for an inter-organization framework to understand the status and roles each one of them has to play for successful implementation of good governance of data.

\section{Blockchain Technology and Livestock Data Management}

Blockchain is a type of Distributed Ledger Technology (DLT) that has been defined as a "distributed, shared, encrypted database that serves as an irreversible and incorruptible repository of information" [20]. Participants of the network called miners are responsible for adding a record of the most recent transactions to the chain after validating the transaction. The process of mining involves calculation of the hash for each block which is computationally or economically complex [21]. According to Swan [22], a registry and inventory system for recording, tracking, monitoring, and transacting of all assets could be managed with Blockchain. Paik et al. [23] note that BCT enhance data quality, provides transparency, immutability, trust and ensures a consistent data store. Additionally, BCT can be used to simplify data management by ensuring trust and security of information across agencies [24]. The implementation of Blockchain is perceived to have a transformative effect on a number of use case applications [25], which is the motivation towards this research study. 
Kenya, recently started installing smart database platforms based on Blockchain in health departments, national transport sector (NTSA and Uber), registration of persons, insurance and banking [26], an indicator that the same can be applied in livestock. This aims to bring trust through smart contracts, security surveillance, improved data access speeds and record traceability. Recent studies reveal a growing applicability of BCT in providing agriculture-livestock sector solutions. Most studies focus on livestock supply chain and traceability [27], [28]; livestock statistics [29]; livestock insurance [30], but no study has been conducted to demonstrate how use of BCT impacts data management among key livestock sector actors. Livestock data being a vital resource requires acceptance, reliability and high availability by all the actors in the network for informed decision making.

This study examined the association of TD and LDM among institutions dealing with livestock-related-data and assessed the moderating effect of BCT on this relationship. The study provides a guide to address the challenges with LDM. Based on the literature review, we formulated the following hypotheses and conceptual model.

$\mathrm{H}_{01}$ : Technological Decentralization (TD) has no significant effect on Livestock Data Management (LDM) in Kenya. $\mathrm{H}_{02}$ : $\quad$ Blockchain Technology (BCT) has no significant moderating effect on the relationship between Technological Decentralization (TD) and Livestock Data Management (LDM) in Kenya.

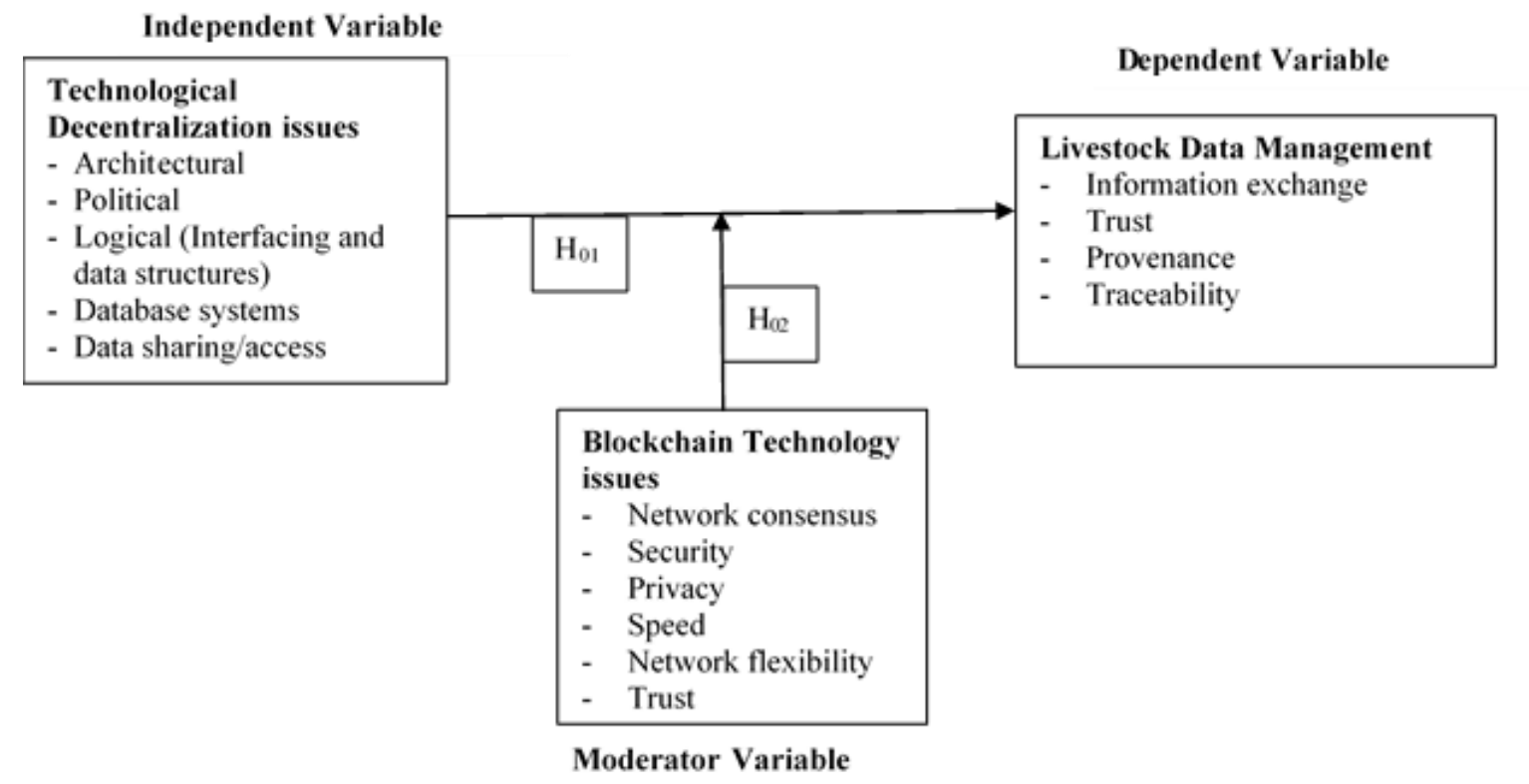

Fig. 1 Conceptual Model

\section{METHODOLOGY}

The study developed a conceptual model to illustrate the interaction, and explored the effect of BCT as a moderator variable between TD issues, as independent variable, encompassing architectural and infrastructure, political and logical issues, data access, retrieval and sharing, database systems and data sources issues and LDM, as dependent variable. A quantitative, hence deductive approach under the positivism paradigm, was deemed appropriate for the study. A crosssectional survey design was used for data collection for the research process. Structured questionnaires consisting of a set of questions and scales with five-point likert scale, 1 indicating strongly disagree, 2 indicating disagree, 3 as neutral, 4 as agree and 5 strongly agree were designed to generate the primary raw data [31]. The questionnaire was structured to measure TD using 5 items, BCT using 6 items and LDM using 5 items. The questionnaires were designed in Open Data Kit (ODK), an online survey tools and sent to respondents to be filled online through a Uniform Resource Locator (URL).

Stratified random sampling technique was used to obtain a true representation of the population that is heterogeneous. The target population in this study included persons involved with livestock-related-data in the respective statutory institutions with an acceptable degree of knowledge in ICT and LDM. The sample size of this study was based on Krejcie et al. [32] statistical table for determining sample size from the given population. The table returned a sample size of 361 employees who were selected from eight institutions. These institutions included Kenya Animal Genetic Resources Centre, Kenya Agriculture and Livestock Research Organization, Kenya National Bureau of Statistics, Kenya Livestock Breeders Association, Kenya Livestock Marketing Council, Livestock Insurance Company, Kenya Veterinary Association, and Livestock Recording Centre. Statistical package for Social Sciences (SPSS) version 24 was used for data analysis and evaluation of the research model. Prior to analysis of the model, validity and reliability consideration 
were duly taken care of in the preparation of research instrument, sampling and data collection process to avoid biases. Factor analysis, further helped achieve this by use of KMO, Chi-Square and Bartlett's test of Sphericity. Cronbach's alpha coefficients $(>=0.7)$ was also tested to ensure the reliability and internal consistency. A hierarchical regression analysis to determine the relationship between variables was also done and results of the models reported.

\section{RESULTS AND DISCUSSION}

\section{A. Descriptive Statistics}

The study presents descriptive statistics for 16 items, as captured in Table I. The responses were received from 324 respondents out of 361 respondents representing $89.8 \%$ response rate. The arithmetic mean measuring central tendency was found to be in the range of 1.685 to 3.0741 for TD, 1.9815 to 2.3519 for LDM and 2.4815 to 3.0185 for BCT. Considering the 5-point Likert scale used in the study, this meant the BCT preference for use was above average. Looking at TD, the item TD4 (3.0741) had the highest statistical mean implying that livestock data was easily accessed, retrieved and shared among institutions. On the other hand, the low statistical mean for item TD1(1.6852) meant that existing infrastructure and architectural systems were not adequate to support LDM. The mean distribution for LDM was average, however LDM1(1.9815) meant that livestock data traceability was a major challenge. Looking at item BCT3(3.0185), a significant proportion of respondents were in agreement that BCT will improve data access speeds. Still, majority of respondents were in agreement that BCT would improve data security, guarantee data privacy, improve data access speeds, ensure consensus and flexibility of networks and improve trust and clarity. The standard deviation across the responses was in the range of 1.08734 to 1.51588 . The standard deviation for each study variable was in the range of 1.08734 to 1.51588 for TD, 1.17902 to 1.36508 for LDM and 1.13198 to 1.38546 for BCT. The relatively high standard deviation value for TD indicated that the variability in the spread of the scores was high while LDM had low standard deviation values pointing at low variability in the responses. The standard errors across the dataset were low in the range of 06041 to 08422 and hence it was concluded that the mean values obtained for all the items and the overall mean were reliable.

Table I Descriptive Statistics

\begin{tabular}{|c|c|c|c|c|c|c|c|}
\hline \multirow[b]{2}{*}{ Code } & \multirow[b]{2}{*}{ Item } & \multirow[b]{2}{*}{$\mathrm{N}$} & \multirow[b]{2}{*}{ Min } & \multirow[b]{2}{*}{ Max } & \multicolumn{2}{|c|}{ Mean } & \multirow{2}{*}{$\begin{array}{l}\text { SD } \\
\text { Std } \\
\text { Dev. }\end{array}$} \\
\hline & & & & & Stat & $\begin{array}{l}\text { Std. } \\
\text { Error }\end{array}$ & \\
\hline & \multicolumn{7}{|l|}{ Technological decentralization (TD) } \\
\hline TD1 & $\begin{array}{l}\text { Existing Infrastructural and architectural systems can } \\
\text { support required computers necessary for livestock data } \\
\text { management }\end{array}$ & 324 & 1 & 5 & 1.6852 & .06041 & 1.08734 \\
\hline TD2 & $\begin{array}{l}\text { The is control of computers and resources by individuals } \\
\text { or organizations in the livestock data management systems }\end{array}$ & 324 & 1 & 5 & 2.3333 & .06057 & 1.09035 \\
\hline TD3 & $\begin{array}{l}\text { The system interfaces and structures can operate } \\
\text { independently and facilitate exchange of livestock data }\end{array}$ & 324 & 1 & 5 & 2.9815 & .07301 & 1.31423 \\
\hline TD4 & $\begin{array}{l}\text { Institutional data on livestock can easily be accessed, } \\
\text { retrieved and shared }\end{array}$ & 324 & 1 & 5 & 3.0741 & .08422 & 1.51588 \\
\hline \multirow[t]{2}{*}{ TD5 } & $\begin{array}{l}\text { Database systems are distributed and there exist an agreed } \\
\text { framework for data sources by institutions }\end{array}$ & 324 & 1 & 5 & 2.2593 & .06788 & 1.22186 \\
\hline & \multicolumn{7}{|l|}{ Livestock Data Management (LDM) } \\
\hline LDM1 & Data on livestock is traceable & 324 & 1 & 5 & 1.9815 & .07379 & 1.32829 \\
\hline LDM2 & Provenance is guaranteed in livestock data management & 324 & 1 & 5 & 2.3148 & .07249 & 1.30478 \\
\hline LDM3 & Information exchange on livestock is easily achieved & 324 & 1 & 5 & 2.2778 & .06550 & 1.17902 \\
\hline LDM4 & Data on livestock is easily accessed & 324 & 1 & 5 & 2.3519 & .07584 & 1.36508 \\
\hline \multirow[t]{2}{*}{ LDM5 } & Provenance is guaranteed in livestock data management & 324 & 1 & 5 & 2.2778 & .06550 & 1.17902 \\
\hline & \multicolumn{7}{|l|}{ Blockchain Technology (BCT) } \\
\hline BCT1 & Block Chain Technology ensures security of data & 324 & 1 & 5 & 2.4815 & .06578 & 1.18412 \\
\hline BCT2 & Block chain technology guarantees privacy of data & 324 & 1 & 5 & 2.8148 & .07028 & 1.26502 \\
\hline BCT3 & Blockchain technology ensures improved data access speed & 324 & 1 & 5 & 3.0185 & .06289 & 1.13198 \\
\hline BCT4 & Block chain technology has network consensus & 324 & 1 & 5 & 2.9815 & .07609 & 1.36960 \\
\hline BCT5 & Block chain technology has network flexibility & 324 & 1 & 5 & 2.8889 & .07697 & 1.38546 \\
\hline BCT6 & Blockchain technology improves trust and clarity & 324 & 1 & 5 & 2.5000 & .07400 & 1.33191 \\
\hline
\end{tabular}


Vol. 9, Issue 5, May 2020

B. Validity and Reliability

The Kaiser-Meyer-Olkin (KMO) was used to check for validity. The value of KMO for each construct $(.704, .871$ and.795) was above the recommended acceptable level of 0.7. The Bartlett's test was significant with Chi-Square= 987.254(p-value < 0.05), Chi-Square $=1568.193$ (p-value $<0.05)$ and Chi-Square $=486.707(\mathrm{p}$-value $<0.05)$ for TD, LDM and BCT respectively and therefore this study continued with PCA. The results are presented in Table II.

Table II KMO and Bartlett's Test

\begin{tabular}{|l|l|l|l|l|l|}
\hline Construct & $\begin{array}{l}\text { No. of } \\
\text { Items }\end{array}$ & KMO & $\begin{array}{l}\text { Bartlett's Test } \\
\text { of Sphericity }\end{array}$ & $\begin{array}{l}\text { Bartlett's Test of } \\
\text { Sphericity Sig. }\end{array}$ \\
\hline Technological Decentralization (TD) & 5 & .704 & 987.254 & .000 \\
\hline Livestock Data Management (LDM) & 5 & .871 & 1568.193 & .000 \\
\hline Blockchain Technology (BCT) & 6 & & .795 & 486.707 & .000 \\
\hline
\end{tabular}

The Cronbach's alpha test gave estimated values that were varying between .773 and .944 . The values indicate that each construct possess high reliability because the value of Cronbach's alpha for each construct is greater than .7. The higher value of Cronbach's alpha for TD (.829), LDM (.944) and BCT (.773) as presented in Table III shows that each construct is internally consistent.

Table III CRONBACH'S Alpha Reliability Coefficient

\begin{tabular}{|l|l|l|l|}
\hline Variable & Constructs & No of items & Alpha \\
\hline Technological Decentralization & & 5 & .829 \\
\hline Blockchain Technology & - & 6 & .773 \\
\hline Livestock Data Management & - & 5 & .944 \\
\hline
\end{tabular}

C. Eigenvalues and Total Variance Explained

The PCA technique with varimax rotation method was used for data reduction. The principle component whose eigenvalue is greater than 1 was used for further analysis. Results indicate that two components for TD had their eigenvalues exceeding 1.0: component 1 (3.097), and component 2 (1.123). The two components explained $84.407 \%$ of the total variance and this confirmed the appropriateness of the factor analysis for TD. Rotated component matrix for TD indicated Items TD1, TD2 and TD5 loaded strongly onto component one. For the second factor, items TD3, and TD4 loaded strongly onto it. For LDM, all the 5 items clustered into a single factor explaining $81.814 \%$ of variance and BCT all the 6 items clustered into a single factor whose value exceeded 1 to explain $47.460 \%$ of variance. The results are as shown in Table IV. The results indicate that the data was obtained from a reliable instrument since all constructs satisfied validity test depicted by strong component loading and convergent validity, eigenvalue of at least 1 .

Table IV Eigenvalues and Total Variance Explained

\begin{tabular}{|l|l|l|l|l|l|l|l|}
\hline Construct & \multirow{2}{*}{ Comp. } & \multicolumn{3}{|c|}{ Initial Eigenvalues } & \multicolumn{3}{l|}{ Rotated Sums of Sq. Loadings } \\
\cline { 4 - 9 } & & Total & $\%$ of Var & Cum \% & Total & \% of Var & Cum \% \\
\hline Technological Decentralization (TD) & 1 & 3.097 & 61.949 & 61.949 & 2.435 & 48.691 & 48.691 \\
\hline Technological Decentralization (TD) & 2 & 1.123 & 22.459 & 84.407 & 1.786 & 35.716 & 84.407 \\
\hline Livestock Data Management (LDM) & 1 & 4.091 & 81.814 & 81.814 & & & \\
\hline Blockchain Technology (BCT) & 1 & 2.848 & 47.460 & 47.460 & & & \\
\hline
\end{tabular}

D. Test of Regression Assumptions

Correlation coefficients of the variables of this study are presented in Table V. LDM correlated with TD significantly and positively $(\mathrm{r}=.675, \mathrm{p}<.01)$, LDM correlated with BCT significantly and positively $(\mathrm{r}=.486, \mathrm{p}<.01)$ and TD correlated with BCT significantly and positively $(r=.480, \mathrm{p}<.01)$.

Table V Correlation Coefficients

\begin{tabular}{|l|l|r|c|c|}
\hline & & 1 & 2 & 3 \\
\hline 1 & Livestock Data Management & 1 & & \\
\hline 2 & Technological Decentralization & $.675^{* * *}$ & 1 & \\
\hline 3 & Blockchain Technology & $.486^{* *}$ & $.480^{* * *}$ & 1 \\
\hline
\end{tabular}


All the associated pairs of variables were significant at level 0.01 hence hypothesized relationships developed were found to be statistically significant at level $\mathrm{p}<0.01$. It indicates that there is a weak association among independent variable and there is no problem of multi-collinearity [33]. The correlation results also indicate the direction of the relationship among all constructs. The relationship between LDM, TD and BCT is positive. The direction of relationship among constructs confirms the results of this study.

\section{E. Regression Analysis Moderation Results}

The moderating effect of BCT on the relationship between TD and LDM was evaluated by using a stepwise hierarchical regression model to test hypothesis $\mathrm{H}_{01}$ and $\mathrm{H}_{02}$. In the model, the independent variable was TD while BCT was the moderating variable. To test the effect of moderation caused by BCT, an Interaction Term, the cross product of TD and BCT was introduced in the second step of the model. Results indicate that TD was positively and significantly associated with $\mathrm{LDM}$ across the models $\left(\beta=.801, \mathrm{Ad} . \mathrm{R}^{2}=.453, \mathrm{~T}=16.4, \mathrm{~F}(1,321)=268.954, \mathrm{p}=0.0000\right.$ and $\beta=.397, \mathrm{~T}=.056$, $\mathrm{F}(1,321)=124.687, \mathrm{p}=0.0388)$.

The results of the moderation in the second step showed that BCT had a positive and significant effect to LDM ( $\beta=.646$, $\mathrm{T}=.089, \mathrm{p}=0.0001)$. The results after introducing the Interaction Term (TD*BCT) showed that the association between TD and LDM was positive and significant $\left(\beta=.346, \mathrm{R}^{2}=.50, \mathrm{~T}=.25, \mathrm{~F}(1,321)=34.420, \mathrm{p}=0.0000\right)$. The value of $\mathrm{R}^{2}$ indicated that the interaction effect when BCT is introduced as a moderator variable, accounts for $5 \%$ added variation in LDM. The $F$ value of $(F(1,320)=34.420, p=0.000)$ showed that the model was fit and significant since $\mathrm{p}<0.05$. The results of moderation analysis are reported in Table VI.

Table VI Moderation Analysis

\begin{tabular}{|c|c|c|c|c|c|c|c|c|}
\hline \multicolumn{9}{|c|}{ Dependent Variable: Livestock Data Management } \\
\hline Model & Variable & $\beta$ & $\mathbf{R}$ & $\Delta \mathbf{R}^{2}$ & Ad. $\mathbf{R}^{2}$ & Tol. & F.Stat & Sig. \\
\hline \multirow[t]{2}{*}{1} & Constant & .264 & .675 & 455 & .453 & 2.039 & 268.954 & .0000 \\
\hline & Technological decentralization & $.801(.675)^{*}$ & & & & 16.4 & & \\
\hline \multirow[t]{4}{*}{2} & Constant & $2.502(.487)^{*}$ & .734 & & & 1.000 & 124.687 & .0000 \\
\hline & Technological decentralization & $.395(.191) *$ & & .489 & & .056 & & .0388 \\
\hline & Block Chain Technology & $.646(.167) *$ & & & & .089 & & .0001 \\
\hline & Interaction Term (TD*BCT) & $.346(.059) *$ & & .050 & & .25 & 34.420 & .0000 \\
\hline
\end{tabular}

Values of standardized regression coefficients, with standard errors in parenthesis $* p<0.05$

\section{F. Discussion of Results}

The first step of the model used direct effects to test the first hypothesis $\left(\mathrm{H}_{01}\right.$ : Technological Decentralization has no significant effect on Livestock Data Management in Kenya) and rejected it because the results showed that TD has a positive significant effect on LDM. This findings are in tandem with Langat et al. [10] findings about the use and impact of ICT in management of livestock data. The study undertaken therefore shows that LDM correlates positively with TD. The more institutions adopt TD the better livestock data is managed. This is supported by the study by Locker [34], indicating that TD allows data generated and stored at source to be easily presented to the user or analytic tool and has a positive effect of enhancing the management of data in the institution.

The hypothesis $\left(\mathrm{H}_{02}\right.$ : Blockchain Technology has no significant moderating effect on the relationship between Technological Decentralization and Livestock Data Management in Kenya) was also rejected on the basis of the test findings. Thus, it can be stated that BCT has a moderating and a significant relationship effect between TD and LDM. This findings confirms the study conducted by Cheng et al. [24] that BCT facilitates data management among agencies by providing data security, data storage and can be used to offer networked services. This findings also showed that BCT implementation is perceived to bring a transformative effect in data management [25]. The study reveals that adoption of BCT by institutions strengthens the association between TD and LDM.

\section{CONCLUSION}

The aim of the study was to assess the moderating effect of BCT of the relationship between TD and LDM among institutions dealing with livestock-related-data in Kenya. BCT measured 6 factors (data security, data privacy, data access speeds, network consensus, network flexibility, trust and clarity) moderating between TD and LDM. The results showed that BCT significantly and positively influenced the relationship between TD and LDM. Additionally, a significant number of respondents agreed that BCT will improve access to livestock data and ensure improved data-access speeds. This is in tandem with Paik et al. [23] who noted that BCT improves data access among all participants on the Blockchain network. Understanding Blockchains with regard to the data management will help application developers design and implement a blockchain-based application for LDM more effectively. The contribution of this study is to present the value of inclusion of BCT in data management by livestock sector actors. Looking beyond digital currencies, the use of 


\title{
International Journal of Advanced Research in Computer and Communication Engineering
}

\author{
Vol. 9, Issue 5, May 2020
}

BCT can bridge existing gaps in livestock data management and consequently improve livestock production, create trust among institutions, improve trade and enhance evidence-based decision-making in the livestock industry.

Admittedly, institutions dealing with livestock-related-data should develop policies and frameworks while adopting BCT as one way to ensure data governance. Given that BCT requires participants working in a network to have consensus, institutions should be ready to invest in resources (personnel, software systems and hardware) and create an enabling environment for BCT adoption.

\section{REFERENCES}

[1] U. Pica-Ciamarra et al., "Investing in the Livestock Sector: Why Good Numbers Matter, A Sourcebook for Decision Makers on How to Improve Livestock Data," Invest. Livest. Sect. Why Good Numbers Matter, A Sourceb. Decis. Makers How to Improv. Livest. Data, 2014, doi: $10.1596 / 17830$.

[2] Roy Behnke and David Muthami, “The contribution of livestock to the Kenyan economy,” IGAD Livest. Policy Initiat. Work. Pap., no. 3-11, pp. 1-62, 2011.

[3] T. P. Robinson, G. Franceschini, and W. Wint, “The Food and Agriculture Organization's Gridded Livestock of the World.," Vet. Ital., vol. 43, no. 3, pp. 745-51, 2007.

[4] (FAO) Ugo Pica-Ciamarra, (FAO- World Bank) Morgan Nancy, and (ILRI) Baker, Derek, "Livestock Indicators for Effective Investments in Developing Countries," no. 8, 2010.

[5] I. S. Kosgey, S. M. Mbuku, A. M. Okeyo, J. Amimo, J. Philipsson, and J. M. Ojango, "Institutional and organizational frameworks for dairy and beef cattle recording in Kenya: a review and opportunities for improvement," Anim. Genet. Resour. génétiques Anim. genéticos Anim., vol. 48, pp. 1-11, 2011, doi: 10.1017/S2078633610001220.

[6] Gabriel Rugalemala and Willy Bett, "Investing in use of data key to growth in agriculture in Kenya - Kenya | ReliefWeb," 2017. [Online]. Available: https://reliefweb.int/report/kenya/investing-use-data-key-growth-agriculture-kenya. [Accessed: 01-Oct-2018].

[7] W. B. Group, World Development Report 2016: Digital Dividends. The World Bank, 2016.

[8] IFPRI/FAO/IICA, "Worldwide Extension Study. GFRAS - Kenya," 2011. [Online]. Available: https://www.g-fras.org/en/world-wide-extensionstudy/africa/eastern-africa/kenya.html. [Accessed: 02-Feb-2018].

[9] O. Elijah, T. A. Rahman, I. Orikumhi, C. Y. Leow, and M. N. Hindia, “An Overview of Internet of Things (IoT) and Data Analytics in Agriculture: Benefits and Challenges,” IEEE Internet Things J., vol. 5, no. 5, pp. 3758-3773, 2018, doi: 10.1109/JIOT.2018.2844296.

[10] R. J. Langat, K. O. Litondo, and J. F. Ntale, "Information Communication Technologies and Marketing Decisions Among Small Scale Farmers in Kenya: Review of Evidence," Int. J. Econ. Commer. Manag. United Kingdom, vol. IV, no. 4, pp. 1167-1180, 2016.

[11] M. Crosby, Nachiappan, P. Pattanayak, S. Verma, and V. Kalyanaraman, “BlockChain Technology: Beyond Bitcoin,” Appl. Innov. Rev., no. 2, pp. 6-19, 2016, doi: 10.1515/9783110488951.

[12] F. Getachew, S. Worku, W. Esatu, T. Dessie, and A. Ababa, "Unleashing the Power of Data in Transforming Livestock Agriculture in Ethiopia," pp. 1-7, 2019.

[13] MoLD, "Republic of Kenya Ministry of Livestock Development. Session Paper NO: 2 of 2008 on November 2008," no. 2, pp. 1-53, 2008.

[14] M. Gakuru, K. Winters, and F. Stepman, "Inventory of Innovative Farmer Advisory Services using ICTs," no. February, 2009.

[15] Prachi Juneja, "Centralization and Decentralization," Management Study Guide Content Team. [Online]. Available: https://www.managementstudyguide.com/centralization_decentralization.htm. [Accessed: 02-Mar-2019].

[16] AKIS, "Decentralizing Agricultural Extension: Lessons and Good Practice," Rural Dev. Dep. Environ. Soc. Sustain. Dev. Netw. World Bank, no. August, p. 16, 2000.

[17] Ben Waters, "Decentralizing Technology, Society, and Thought." [Online]. Available: https://hackernoon.com/decentralizing-technologysociety-and-thought-c59318a8aef9. [Accessed: 12-Nov-2019].

[18] Vitalik Buterin, "The Meaning of Decentralization," 2017. [Online]. Available: https://medium.com/@VitalikButerin/the-meaning-ofdecentralization-a0c92b76a274. [Accessed: 29-Sep-2018].

[19] E. W. Barasa, A. M. Manyara, S. Molyneux, and B. Tsofa, "Recentralization within decentralization: County hospital autonomy under devolution in Kenya," PLoS One, vol. 12, no. 8, pp. 1-18, 2017, doi: 10.1371/journal.pone.0182440.

[20] A. Wright and P. De Filippi, "Decentralized Blockchain Technology and the Rise of Lex Cryptographia," Ssrn, 2015, doi: 10.2139/ssrn.2580664.

[21] D. Kochin, "Where do decentralized applications store their data?," 2017. [Online]. Available: https:/github.com/TiesNetwork/tiesdocs/wiki/Where-do-decentralized-applications-store-their-data\%3F. [Accessed: 17-Sep-2018].

[22] Swan Melanie, Blockchain: Blueprint for a New Economy - Melanie Swan - Google Books. O’Reilly Media, Inc, 2015.

[23] H. Y. Paik, X. Xu, H. M. N. D. Bandara, S. U. Lee, and S. K. Lo, "Analysis of data management in blockchain-based systems: From architecture to governance," IEEE Access, vol. 7, pp. 186091-186107, 2019, doi: 10.1109/ACCESS.2019.2961404.

[24] Steve Cheng et al., "Using blockchain to improve data management in the public sector," Digit. McKinsey, no. February 2017 , pp. 1-10, 2017.

[25] Buterin Vitalik, "On Public and Private Blockchains," 2015. [Online]. Available: https://blog.ethereum.org/2015/08/07/on-public-and-privateblockchains/. [Accessed: 09-Sep-2018].

[26] O. A. KARIUKI JAMES, “Blockchain roots deepen in Kenya - Daily Nation,” 12-Sep-2017.

[27] F. Marinello, A. Pezzuolo, S. E. E. Profile, E. Rq, and E. Whfkqrorj, "Development of a traceability system for the animal product supply chain based on Blockchain Technology," no. September, 2017.

[28] C. N. Hancock, "ScholarlyCommons The Integration of Blockchain Technology to the Beef Industry - A Comparative Analysis The Integration of Blockchain Technology to the Beef Industry - A Comparative," pp. 10-31, 2019.

[29] T. R. S. Go-, "Potential use of Blockchain for Livestock Statistics in Vietnam Final report," no. December, 2018.

[30] "RippleNami | RippleNami Powers Kenya's First Real-time Livestock Traceability Programme Enabling Trade and Food Safety,” 2018. [Online]. Available: https://ripplenami.com/ripplenami-powers-kenyas-first-real-time-livestock-traceability-programme-enabling-trade-and-food-safety/. [Accessed: 22-Sep-2018].

[31] C. McDaniel and R. H. Gates, Marketing research.

[32] R. V. K. and D. W. Morgan, "DETERMINING SAMPLE SIZE FOR RESEARCH ACTIVITIES," 1998.

[33] A. Field, Discovering statistics using SPSS, 2nd ed., vol. 50, no. 04. SAGE PublicationsSage UK: London, England, 2005.

[34] Lockner Julie, "Is Data Decentralization the New Trend? | Sandhill," 2015. [Online]. Available: http://sandhill.com/article/is-datadecentralization-the-new-trend/. [Accessed: 28-Sep-2018]. 